\title{
ОСОБЕННОСТИ ОТНОШЕНИЙ К ДРУГИМ ЛЮДЯМ ЖИТЕЛЕЙ ГОРОДОВ ЮГА РОССИИ, ДИФФЕРЕНЦИРОВАННЫХ ПО ТЕРРИТОРИАЛЬНО- ПРОСТРАНСТВЕННО-ВРЕМЕННЫМ ПАРАМЕТРАМ ПРОЖИВАНИЯ В ГОРОДЕ
}

\author{
Шкурко Татьяна Алексеевна \\ Балакина Анна Андреевна
}

Исследование выполнено при финансовой поддержке ЮФу

(грант «Угрозы начиональной безопасности в условиях геополитической конкуренции и модели агрессивного и враждебного поведения молодежи», тема № 213.01-07-2014/15ПЧВГ (проектная часть внутреннего гранта ЮФУ))

В статье систематизированы территориально-пространственновременные факторы, влияющие на формирование отношений к другим людям, определено их дифференцированное влияние на выраженность социально-психологических потребностей, параметров и типов отношений к другим людям жителей мегаполиса, большого и малого городов. В качестве детерминант особенностей отношений к другим людям в исследовании рассматриваются: место рождения (город проживания/другой город); район проживания (центр/периферия); тип проживания (частный дом, коттедж) многоквартирный дом); высота (этаж) проживания; длительность проживания в городе; наличие и количество переездов; тип переезда (своя область/свой регион/другой регион/другая страна); чель переезда. Эмпирическим объектом исследования выступили жители малого (Крымск) и большого (Ростов-наДону) городов Юга России, а также жители мегаполиса (Москва). В работе показано, что влияние территориально-пространственно-временных факторов на систему отношений к другим людям жителя города опосредовано типом города. Наибольшее влияние оказывают такие факторы, как: «место рождения», «тип проживания», «наличие/отсутствие переезда», «тип переезда», «длительность проживания». В работе продемонстрировано, что территориально-пространственно-временные факторы обусловливают в первую очередь отношения к другим людям жителей мегаполиса и большого города, и в меньшей степени влияют на отношения к другим людям жителей малого города.

Результаты и выводы исследования могут быть использованы при анализе, объяснении, прогнозировании общественных явлений на уровне городов различного типа (протестное движение, участие в митингах, 
миграция населения); при организации мероприятий и акций в городской среде; при планировании и реализации предвыборных кампаний для разных челевых групп.

Ключевые слова: отношение, отношение к другим, виды отношений, факторы отношений, территориальные факторы, социально-психологические потребности, город, тип города, житель города, психология среды.

В психологии выделяют четыре группы факторов, опосредующих возникновение и динамику отношений личности (к себе, к другому, к миру) [22], которые относятся либо к «внутренней», либо к «внешней» детерминации. В последнее время исследователи рассматривают в качестве еще одного «внешнего» фактора формирования отношений субъекта территориальнопространственную организацию окружающей его среды $[9,12,14,15,17$, 20]. В ряде публикаций мы обращались к анализу влияния на отношения человека с другими людьми типа города (мегаполис/большой город/малый город) $[2,23,24]$. Данная статья посвящена доказательству гипотезы о том, что выраженность социально-психологических потребностей, параметров и типов отношений к другим людям жителей городов разного типа может быть обусловлена территориально-пространственно-временными параметрами проживания в городе. В современных исследованиях нами обнаружена зависимость отдельных видов отношений к другим людям от определенных территориально-пространственно-временных параметров проживания жителей города, при этом в социальной психологии отсутствует их комплексное изучение в качестве детерминант особенностей отношений к другим. Наиболее изучены, начиная с известных работ Э. Т. Холла [21], границы и зонирование городского пространства $[1,3,4$, 5, 7, 11, 15, 19]. Большое количество работ посвящено анализу таких параметров пространственного зонирования, как «центр/периферия». Центральная часть города характеризуется высокой концентрацией людей на относительно ограниченной территории. Многофункциональность центральной части города вызывает большой приток дневных и вечерних посетителей, создает условия для тесной пространственной близости жителей города, относящихся к различным социальным группам; содействует их взаимному контакту и общению; способствует автоматическому включению жителя центра города в ситуации наблюдения разнообразных повседневных интеракций других людей $[8,9,17,20,26]$. Ряд работ посвящен типу проживания городского жителя, который вносит свои характерные особенности в процесс социализации, в систему отношений с внешним миром и окружающими людьми $[18,19,20,25]$. Исследователи обращаются также к пространственно-временным характеристикам проживания 


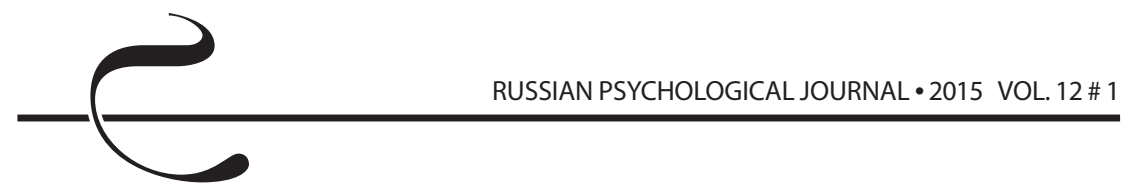

в городе - таким, как длительность проживания в городе, наличие/отсутствие переезда [6, 12, 17].

Проведенный нами анализ показал, что территориально-пространственновременные параметры проживания в городе оказывают существенное влияние на особенности отношений к другим жителей городов разного типа и выполняют ряд функций, среди которых центральное место занимают социально-психологические: коммуникативная, интегративная, социализирующая, информационно-обучающая, стратификационная, развивающая, функция удовлетворения социальных потребностей личности. Территориально-пространственно-временные параметры проживания в городе обусловливают форму и частоту социальных контактов жителей города в условиях повседневного взаимодействия, способствуют формированию территориальной идентичности, детерминируют процессы самовосприятия, самопрезентации и восприятия, оценки, категоризации другого человека, влияют на формирование типов и параметров отношений к другим людям.

В результате систематизации территориально-пространственно-временных факторов, влияющих на формирование отношений к другим людям, мы выделили следующие территориально-пространственные параметры проживания в городе: 1) место рождения (город проживания/другой город); 2) район проживания (центр/периферия); 3) тип проживания (изолированно от других (частный дом, коттедж)/вместе с другими (многоквартирный дом)); 4) высота (этаж) проживания. В качестве пространственно-временных параметров, образующих некий «пространственно-временной путь» личности, под которым мы понимаем систему пространственно-временных передвижений жителя города и специфику выбора им города проживания, нами рассматривались следующие характеристики: 1) длительность проживания в городе; 2) наличие и количество переездов; 3) тип переезда (своя область/свой регион/другой регион/другая страна); 4) цель переезда. В нашем исследовании мы обращаемся к предложенным В. А. Лабунской в концепции субъекта затрудненного общения базовым модальностям отношений человека к другим людям: доброжелательность, принятие, доверие, враждебность, манипулятивное отношение [10].

Методический инструментарий исследования составили следующие методы: 1. Авторская анкета «Территориально-пространственный путь личности», с помощью которой нами определялись территориально-пространственновременные параметры, по которым производилась дифференциация жителей города. 2. Опросник межличностных отношений В. Шутца, адаптированный А. А. Рукавишниковым [16], позволяющий диагностировать выраженность социально-психологических потребностей жителя города (во включении, 
в контроле, в любви на уровнях выраженного и требуемого от других поведения). 3. Блок методик, адаптированных Ю. А. Менджерицкой [10], диагностирующих интенсивность отношений жителей города к другим людям базовых модальностей: 1) «Шкала принятия других» Фейя; 2) «Шкала доброжелательности» Кэмпбелла; 3) «Шкала доверия» Розенберга; 4) «Шкала враждебности» Кука-Медлей (субшкалы «враждебность», «агрессия», «цинизм»); 5) «Шкала манипулятивного отношения» Банта. 4. Цветовой тест отношений А. М. Эткинда [13], использованный с целью диагностики следующих видов эмоциональных, частично неосознаваемых жителями городов отношений: отношения к обобщенному другому (категория «другой человек»); отношения к обобщенным другим, дифференцированным по признаку «свой/чужой» (категории «житель своего города», «житель чужого города», «коренные жители», «приезжие»); отношения к обобщенным другим, дифференцированным по критерию «близкий/далекий» (категории «семья», «родственники», «друзья», «соседи», «коллеги»); отношения к конкретным другим (категории «мать», «отец»). 5. Опросник диагностики основных типов межличностных отношений Тимоти Лири [13].

Эмпирическим объектом исследования выступили: жители Крымска (100 человек), жители Ростова-на-Дону (100 человек) и жители Москвы (120 человек) в возрасте от 21 до 37 лет. Всего в исследовании приняли участие 320 человек. К полученным данным были применены множественный и линейный регрессионные виды анализа, с помощью которых каждый из изученных показателей (выраженность социально-психологических потребностей, параметры и типы отношений к другим людям) проверялся на наличие и тип связи с группой выделенных территориально-пространственно-временных параметров. Регрессионный анализ был проведен отдельно по выборкам жителей мегаполиса, большого (Ростов-на-Дону) и малого (Крымск) городов, чтобы выявить специфику влияния выделенных параметров в зависимости от типа города (табл. 1).

Анализ взаимосвязей, полученных на выборке жителей мегаполиса, позволяет заключить, что среди жителей мегаполиса, чьим местом рождения не является Москва, выявлен достаточно высокий уровень потребности в контроле на уровне требуемого от других поведения (потребности в зависимости) ( $p=0,027)$, а также покорно-застенчивого $(r=0,229, p=0,014)$ и зависимо-послушного ( $r=0,272, p=0,004)$ типов отношений к другим людям. Среди жителей мегаполиса, проживающих в центральной части города, в большей степени выражены доброжелательность, потребности во включении $(r=0,206, p=0,035)$ и в любви $(r=0,207, p=0,035)$ на уровне выраженного поведения, а также обнаружен более высокий уровень интенсивности эмоционального отношения к жителю «своего» города $(r=0,202$, 


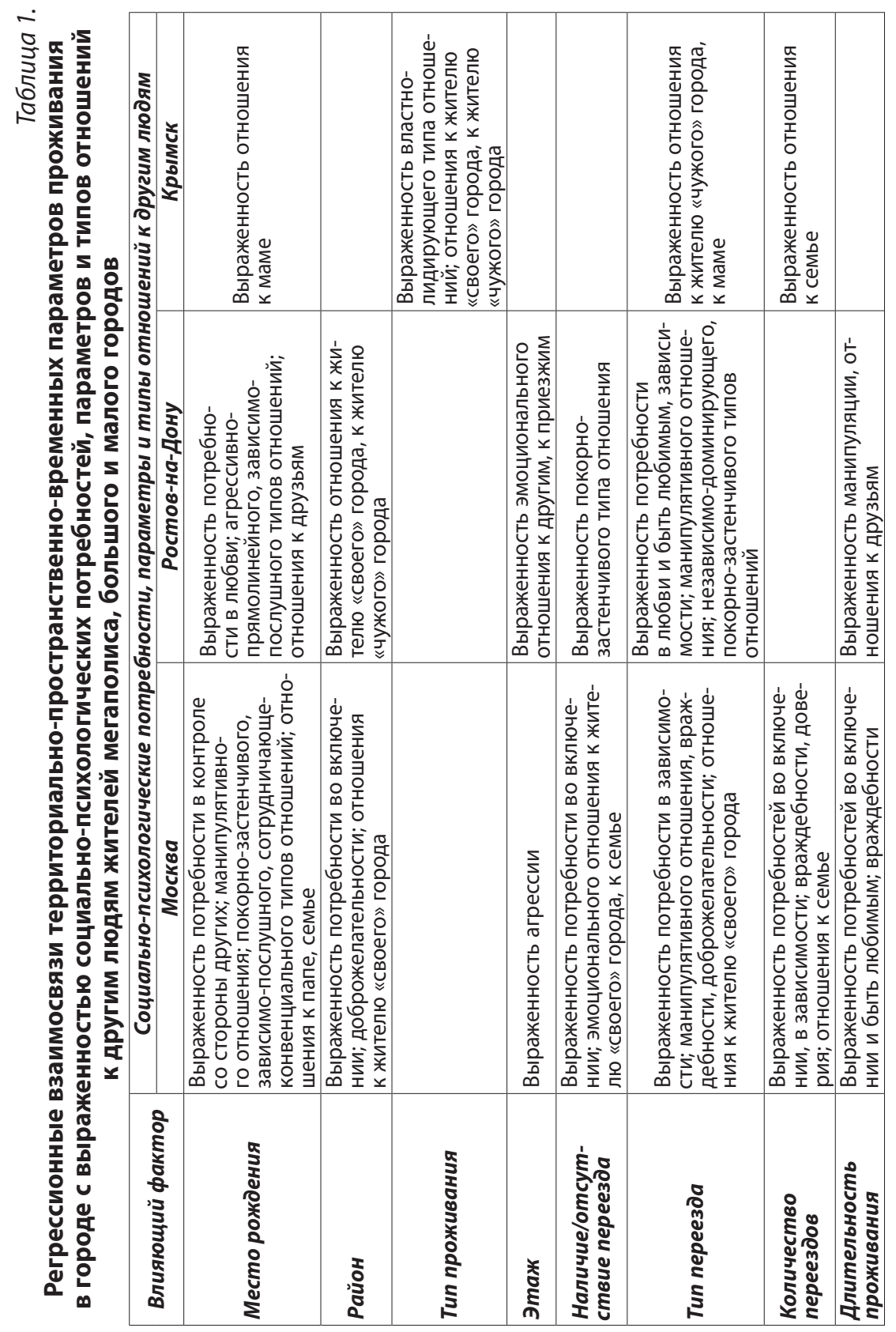


p = 0,032), чем среди жителей периферийных частей городского пространства. Повышение высоты проживания (параметр «этаж проживания») взаимосвязано с увеличением уровня агрессии $(r=0,299, p=0,039)$. Жители мегаполиса, пространственно-временная биография которых включает переезд, отличаются более высоким уровнем выраженности социально-психологических потребностей во включении ( $r=0,235, p=0,015)$ и контроле со стороны других ( $r=0,221, p=0,022)$, интенсивностью эмоционального отношения к жителям «своего» города ( $r=0,182, p=0,037)$, сниженной интенсивностью эмоционального отношения к семье $(r=0,214, p=0,020)$, в то время как отсутствие переезда обусловливает более высокий уровень доброжелательности к другим ( $r=0,259, p=0,043)$. Жители Москвы, переехавшие в мегаполис из другого региона (параметр «тип переезда»), характеризуются высокой выраженностью потребности в контроле со стороны других ( $r=0,213$, $p=0,028)$ и манипулятивного отношения к другим $(r=0,241, p=0,009)$. Типы переездов в мегаполис из Центрального федерального округа и Московской области детерминируют соответственно невысокую выраженность доброжелательности ( $r=0,189, p=0,041)$ и враждебности по отношению к другим людям ( $r=0,229, p=0,014)$, а также более высокий уровень интенсивности отношения к жителю «своего» города $(r=0,182, p=0,049)$. С увеличением количества переездов (параметр «количество переездов») увеличивается уровень выраженности потребностей во включении $(r=0,203, p=0,036)$ и контроле со стороны других ( $r=0,221, p=0,022)$, при этом снижается уровень доверия $(r=0,187, p=0,044)$ и враждебности по отношению к другим людям ( $r=0,193, p=0,039)$, а также интенсивность эмоционального отношения к семье $(r=0,185, p=0,046)$. С увеличением времени проживания в мегаполисе (параметр «длительность проживания») снижается уровень выраженности социальных потребностей во включении и в любви со стороны других, интенсивность агрессивного отношения к другим людям.

Обратимся к анализу взаимосвязей, полученных на выборке жителей большого города. Участники исследования, родившиеся в Ростове-на-Дону, характеризуются более высоким уровнем выраженности агрессивнопрямолинейного отношения к другим людям ( $(=0,040)$; у жителей, рожденных не в городе проживания, преобладает зависимо-послушный тип межличностных отношений ( $p=0,042)$, а также они испытывают меньшую потребность в установлении близких эмоциональных отношений с другими людьми $(r=0,218, p=0,041)$ по сравнению с другими жителями. Жители Ростова-на-Дону, проживающие на периферии города, демонстрируют более высокий уровень интенсивности эмоционального отношения к жителю как «своего» $(r=0,261, p=0,014)$, так и «чужого» городов $(r=0,307, p=0,05)$. Была обнаружена взаимосвязь между параметром «этаж проживания» и более 
высоким уровнем интенсивности неосознаваемого отношения к категориям «другие» $(r=0,286, p=0,005)$ и «приезжие» $(r=0,240, p=0,080)$. Параметр «наличие/отсутствие переезда» обусловливает более высокую выраженность покорно-застенчивого типа межличностных отношений среди тех жителей Ростова-на-Дону, биография которых включает переезд ( $r=0,243, p=0,037)$. Жители Ростова-на-Дону, переехавшие в него из города в другом регионе, демонстрируют более низкий уровень выраженности потребности в любви со стороны других людей $(r=0,232, p=0,030)$, независимо-доминирующего типа межличностных отношений $(r=0,213, p=0,046)$ и высокую интенсивность покорно-застенчивого типа отношения к другим людям ( $r=0,345, p=0,001)$. Жители, переехавшие в Ростов-на-Дону из другой страны, характеризуются высоким уровнем потребности в контроле со стороны других ( $r=0,216$, $p=0,0443)$, невысокой выраженностью потребности в любви $(r=0,241$, $p=0,023)$, выраженной агрессией $(r=0,222, p=0,038)$ и манипулятивным отношением к другим людям, а также более высоким уровнем интенсивности эмоционального отношения к «приезжим» $(r=0,234, \mathrm{p}=0,022)$.

Жители малого города, проживающие в частном доме, демонстрируют более высокий уровень выраженности властно-лидирующего типа отношений к другим людям, а также интенсивность отношения к жителю «чужого» города $(r=0,228, p=0,049)$, чем жители многоквартирных жилых домов. Жители Крымска, проживающие в многоквартирных домах, демонстрируют более высокую интенсивность эмоционального отношения к жителю «своего» города $(r=0,259, p=0,012)$. Фактор «тип переезда» (из города, расположенного в данном или другом регионе) обусловливает более низкий уровень интенсивности эмоционального отношения к жителю «чужого» города ( $r=0,034$, $p=0,012)$. У жителей Крымска, переехавших в этот город из другого региона, интенсивность эмоционального отношения к своей матери значительно выше по сравнению с другими жителями города ( $r=0,199, \mathrm{p}=0,047)$. Обнаружено, что увеличение количества переездов взаимосвязано со снижением интенсивности эмоционального отношения к категории «мама».

Обобщая полученные в исследовании результаты, можно сделать ряд выводов: 1. Территориально-пространственно-временные факторы влияют на выраженность социально-психологических потребностей, параметров и типов отношений к другим людям жителя города. 2. Влияние территориальнопространственно-временных факторов на систему отношений к другим людям жителя города опосредовано типом города (мегаполис/большой город/ малый город). 3. Наибольшее влияние оказывают такие территориальнопространственно-временные факторы, как: «место рождения», «тип проживания», «наличие/отсутствие переезда», «тип переезда», «длительность проживания». 4. Территориально-пространственно-временные факторы обусловливают 
в первую очередь отношения к другим людям жителей мегаполиса и большого города, и в меньшей степени влияют на отношения к другим людям жителей малого города. 5. Территориально-пространственно-временные параметры проживания в городе задают в первую очередь выраженность социальнопсихологических потребностей, а также интенсивность эмоциональных, частично неосознаваемых отношений к другим людям, дифференцированным по критериям «свой»/«чужой», «близкий»/«далекий».

Результаты исследования позволяют прогнозировать социальное поведение человека на уровне городов различного типа (миграционные процессы, особенности социальной адаптации и т. д.), учитывая социальнопсихологический потенциал территориально-пространственно-временных параметров проживания в городе.

\section{Литература}

1. Аскаров Ш.Д. Регион. Пространство. Город. - М., Стройиздат, 1998.

2. Балакина А. А., Шкурко Т. А. Образ города и особенности отношения к Другому жителей мегаполиса и крупного города (на примере г. Москвы и г. Ростова-на-Дону) // Северо-Кавказский психологический вестник. 2011. - T. 9. - № 3. - С. 5-9.

3. Барсукова С. Тенденции социального зонирования российских городов / Российское городское пространство: попытка осмысления. - М.: Монф, 1999. - С. 92-111.

4. Бикбов А. Москва/Париж: пространственные структуры и телесные схемы // Логос. - 2002. - № 3. - С. 72-95.

5. Бляхер Л. Е. Государство и несистемные сети «желтороссии», или заполнение «пустого пространства» // Политика. - 2010. - № 1. - С. 69-81.

6. Глазычев В. Л. Воспитание пространства // Знание-сила. - 2004. - Август. - С. 39-46.

7. Иовлев В. Экопсихология для архитекторов: процесс, форма. - Екатеринбург: Архитектон, 1996.

8. Карпов А. Е. Имплозия городского пространства: проблема существования центра города современной России / Российское городское пространство: попытка осмысления. - М.: Московский общественный научный фонд, 2000.

9. Круусвал Ю. Детерминация образа жизни семьи в городской среде. Человек, среда, общение. - Таллин, 1980.

10. Лабунская В. А., Менджерицкая Ю. А., Бреус Е. Д. Психология затрудненного общения: Теория. Методы. Диагностика. Коррекция. - М., 2001.

11. Махлина С. Т. Семиотика культуры повседневности. - СПб.: Алетейя, 2009. 
12. Милграм Cm. Эксперимент в социальной психологии. Человек в большом городе. - СПб.: Питер, 2000.

13. Общая психодиагностика. Под редакцией А. А. Бодалева, В. В. Столина. - М., 1987.

14. Панов В. И. Экопсихологические взаимодействия: виды и типология // Социальная психология и общество. - 2013. - № 3. - С. 13-28.

15. Парк Р. Э. Городское сообщество как пространственная конфигурация и моральный порядок // Социальные и гуманитарные науки. - 2000. Серия 11. - № 3. - С. 136-150.

16. Рукавишников А. А. Опросник межличностных отношений. - Ярославль, 1992.

17. Сазонов Д. Н. Социально-психологические особенности репрезентации городской пространственно-предметной среды у жителей города: дисс. ... канд. психол. наук. - Белгород, 2009.

18. Смолова Л. В. Безопасность городской среды в восприятии жителей с позиции психологии взаимодействия с окружающей средой / Обретение Астаной столичного статуса: Сборник докладов 2-ой Международной научной конференции. - Астана, 2009. - С. 53-62.

19. Солодилова Л. А. Методы предпроектного анализа. - Ростов-на-Дону: Изд-во Рост. гос. акад. архит. и иск-ва, 2006.

20. Хейдметс М. Феномен персонализации среды: теоретический анализ / Личность и предметно-пространственная среда. - Краснодар: Изд-во КубГУ, 2000. - С. 88-112.

21. Холл Э. Как понять иностранца без слов. - М.: Вече-Персей-Аст, 1995.

22. Шкурко Т. А. Концепция отношений личности / Социальная психология личности в вопросах и ответах: учебное пособие под ред. В. А. Лабунской. - М.: Гардарики, 1999. - С. 129-142.

23. Шкурко Т. А. Отношения к «своим/чужим», «близким/далеким» жителей городов разного типа // Социальная психология и общество. - 2013. № 4. - С. 81-94.

24. Шкурко Т. А., Балакина А. А. Социально-психологические особенности отношений к другим людям жителей мегаполиса, большого и малого городов // Северо-Кавказский психологический вестник. - 2012. - Т. 10. № 3. - С. 36-40.

25. Шмерлина И. Социальная экология соседства // Социальная реальность. - 2006. - № 9. - С. 59-71.

26. Lauristin M. Public participation as an educational process: An East European view / Cities of Europe: The Public's Role in Shaping the Urban Environment. Moscow Publ., 1991. - pp. 117-131. 